\title{
Evaluating the road safety of local municipalities with application of GRA: Montenegro case study
}

\author{
Mirjana Grdinić-Rakonjac, Vladimir Pajković \\ Faculty of Mechanical Engineering, University of Montenegro, Džordža Vašingtona, Podgorica, 81000, Montenegro
}

\begin{abstract}
Evaluation of road safety is the core of road safety management, and to prevent traffic accidents, an understanding of the factors that cause them is essential. Currently, road safety experts show great interest in finding one fair approach to evaluate and compare road safety situations in different territories. Previously, the assessment of the situation and comparisons were based on the size of the consequences in traffic accidents but recently, the road safety experts turned to observing and comparing safety indicators as a more humane approach, given that in this way critical aspects can be seen at an early stage and before accidents occur. Over time, an approach of describing the road safety situation with a composite index has been developed in which a large number of indicators have been aggregated. The composite traffic safety index is a useful tool in assessing the safety situation that provides comparison, monitoring and communication between different territories and defines the elements of the system that need to be improved. The methodological development of the index construction continues today. The main steps of the mentioned process are the selection of the relevant set of indicators and determining the influence of each of them. In this paper, a set of ten hierarchical road safety indicators in terms of final outcomes, the road users' behavior and basic territory information are weighted with grey relational analysis and aggregated in order to calculate one composite index score of 21 municipalities of Montenegro. Grey relational analysis can measure the relative importance among indicators, implying that those with higher grey weight values are more significant than those with lower grey weights. However, it cannot be claimed that indicator with the highest weight has the greatest impact on accidents occurrence, but it certainly indicates a field where strategies can be adopted to improve level of road safety.
\end{abstract}

Keywords: road safety; local municipalities; grey relational analysis; case study

\section{INTRODUCTION}

Traffic safety is a global problem and the high number of loss lives and high economic damage require a serious approach in order to reduce the number of accidents and their consequences. At the national level, accidents result in high financial costs which particularly affect developing countries. According to two of the leading causes of death by injury in the world are road deaths and traffic injuries. In addition, many countries have launched actions and strategies in order to achieve the goal of a $50 \%$ reduction of both accidents and injuries. As WHO (2018) reported, 132 countries have launched funded strategies at the national level, and the reduction of road deaths has been set as a national goal by 109 countries. Montenegro is one of developing non-European Union (EU) countries in the Western Balkans that attempts to fulfil the regulations of the EU and the United Nations (UN). In addition, the National Coordination Board of Montenegro has adopted the Strategy for Improvement of Road Traffic Safety 2010-2019, with the main goal of reducing traffic injuries and fatalities by $30 \%$ and $50 \%$, respectively, by 2019 compared to the 2007 figures. However, at present, this goal does not seem to have been achieved yet. The total number of 25,100 traffic fatalities in 2018 in the EU (EC, 2010) represents a $21 \%$ decrease in the number of road deaths compared to the 31,500 road deaths in 2010 (WHO, 2011). Data from Montenegro show a decrease of $50 \%$ in road deaths in 2018 compared to 2010 , and a decrease of approximately $20 \%$ when compared to 2011 (all Montenegro data are collected from the Ministry of Interior). When comparing these figures to the European average number of fatalities per million inhabitants (i.e., 49), Montenegro's rate in 2018 was 77 , which is comparable to the worst-performing EU countries, namely, Romania (i.e., 98), Bulgaria (i.e., 88), Latvia (i.e., 78), and neighboring Croatia (i.e., 77), (WHO, 2018). 
For adequate and authoritative measures that will improve traffic safety, it is necessary to primarily perform an analysis of the current, existing situation. Great efforts are being made to reduce the number and consequences of traffic accidents to a minimum with the aim of adopting better and more precise strategies, comparison between territories, regions, countries, etc. Theoretically, countries can be compared on each risk domain or indicator separately. Previously, the assessment of the situation and comparisons were based on the size of the consequences in traffic accidents, such as the comparison of the number of fatalities presented in relation to the number of inhabitants or the number of accidents presented in relation to the number of motor vehicles, etc. One of the main disadvantages of crash related variables is that although they indicate the relative position of a country they cannot offer suggestions on how to reduce the number of crashes and casualties. To this respect, The European Transport Safety Council advised the European Union in 2001 to formulate and specify a set of relevant safety performance indicators that can be used on the European and national level as a means to determine trends in the level of road safety and the success of casualty reduction programs (Bao, 2010). In recent years, an approach that represents the state of safety using the road safety composite index (CI) has become popular. CI is an assessment of the state of traffic safety in which all selected indicators are implemented and will in a simple and adequate way show the size of the problem in a certain territory enabling its comparison with others. Using a composite index, aspects and domains that need special treatment can be determined in order to improve traffic safety. To integrate a large number of safety factors into one value, the three mandatory steps are defined in the literature (OECD \& EC, 2008): selection and quantification of relevant traffic safety indicators, weight assignment to selected indicators and aggregation of selected indicators in the final assessment of traffic safety. No universal approach exists between countries, which consequently results in a large number of methods for index development and benchmarking of road safety. An additional problem is the different types of data collected by different countries, especially undeveloped countries such as Montenegro, which do not have the same laws and do not yield to the same regulations as developed countries. In spite of the thorough effort to provide the data, it should be realized that it is difficult to obtain quantitative and unbiased estimates on the actual implementation of road safety policies and programs. Related to previously mentioned, in this paper, part of uncertainty theory, namely grey relational analysis was used to construct composite indicator.

\section{LITERATURE REVIEW}

One of the most important indicator related research studies was the SafetyNet project (Hakkert, Gitelman \& Vis, 2007b) within which the theoretical assumption for road safety indicators was presented, although it did not combine the indicators into one composite value. This project served as a base for further research in this field and was a component of the SUNflower project (Wegman, Commandeur, Doveh \& Eksler, 2008) in which the authors proposed grouping of territories according to their safety level and assignment of weight to each of them using principal component and factor analysis to create an overall safety index. In 2008, the European Commission and OECD (2008) published a handbook for constructing road safety composite indicators and proposed the following weighting methods: weights based on principal component analysis, data envelopment analysis, analytic hierarchy process, benefit of the doubt approach, budget allocation process, unobserved components model, conjoint analysis and public opinion; and aggregation methods: additive (weighted sum approach), geometric aggregation and non-compensatory multi-criteria aggregation. Hermans, Van den Bossche \& Wets (2008b) combined the indicators in one performance indicator by assigning weights to each and used five weighting methods that were applied to the road safety data from various countries and Gitelman, Doveh \& Hakkert (2010) proposed composition of a road safety index by combining the basic indicators using weights based on statistical models. Composition of one road safety indicator is currently receiving increased attention in the literature as well as the use of various methodologies for that purpose. Therefore, it is surprising that few studies in the literature use grey relational analysis in this effort.

Grey relational analysis (GRA) is multidisciplinary tool and it is successfully used in various fields such as economics, management, decision-making, medicine, prediction, modelling, and data processing, among others. With respect to road safety, $\mathrm{Lu}$ $\&$ Wevers (2007) used the grey relational method- 
ology for evaluation of road safety in urban roads in Netherland and used GRA to rate the scenarios of infrastructure, advanced driver assistance systems and their combinations, which are expected to be implemented to improve road safety. Ma, Shao, Ma \& Ye (2011) used a combination of the grey and fuzzy theory to create three different sets of composite road safety indicators by considering judgment attitudes: one related to regional roads, one related to urban roads and one related to highways. René, Becker \& Manz (2016) applied the grey system with time series to predict the expected number of accidents and relayed results to target improvement that should be performed and measures that should be conducted. Liu, Huang, Duan \& Zhang (2017) used grey relational analysis to calculate weights for the purpose of constructing a fuzzy road safety indicator. The authors used nine indicators related to the frequency, severity and trend of traffic accidents and applied a fuzzy comprehensive method to obtain the final score. According to above mentioned Road Safety studies, where GRA was successfully implemented, for computing of the composite indicator and evaluating road safety of territory, related to this particular research, novel methodology integrating grey relational analysis (GRA) is proposed. In addition to previous studies, the authors applied a hierarchical structure of indicators and used GRA to calculate indicator weights at each level. Furthermore, additive aggregation is performed to construct one overall composite indicator.

\section{BASIC CONCEPT OF PROPOSED METHODOLOGY}

Grey theory, first proposed by Deng (1989) operates with discrete data that are classified as black (unknown data), grey (incomplete data) or white (accurate data). In other words, it can be said that grey models predict the values of time series based only on the set of the most recent data and can be understood as curve fitting. Grey relational analysis address uncertainty of systems and since road safety indicators data are not entirely reliable regarding the collection methodology, GRA is proposed to process it. The mathematical calculations in GRA are derived as follows:

When data are collected, they are placed in $K$ categories and $L$ layers. Each category of indicators $(k=1, \ldots, K)$ form matrix where indicators represent alternatives $\left(i=1, \ldots, m_{k}\right)$ and territories represent attributes $(j=1, \ldots, n)$. The decision matrix can be presented as follows:

(1) $X_{i}=x_{i}(1), x_{i}(2), \ldots, x_{i}(j), \ldots, x_{i}(n)$

In this paper, authors used normalization in order that larger assigned weight represents greater significance of indicator:

(2) $g_{i}(j)=\frac{x_{i}(j)-\min _{j=1}^{n} x_{i}(j)}{\max _{j=1}^{n} x_{i}(j)-\min _{j=1}^{n} x_{i}(j)}$;

In addition, normalized matrix is derived as G:

(3) $G=\left[\begin{array}{cccc}g_{1}(1) & g_{1}(2) & \cdots & g_{1}(n) \\ g_{2}(1) & g_{2}(2) & \cdots & g_{2}(n) \\ g_{m_{k}}(1) & g_{m_{k}}(2) & \cdots & g_{m_{k}}(n)\end{array}\right]$

Then, the referent data set for normalized matrix is constructed. The referent set represent the virtual ideal set and is formed from the ideal values of attributes, maximum or minimum, depending on the research goal. In a matter in which higher weight represents a larger influence in a road safety situation, the reference set in this particular research is constructed from maximum values.

$G_{0}=\left(g_{01}, g_{02}, \ldots, g_{0 n}\right)$

When the referent set is formed, the grey relational coefficient is calculated by measuring the distance of each indicator value from the referent set as shown in equation (4).

(4) $\zeta_{0 i}(\mathrm{j})=\frac{\Delta_{\min }+\rho \Delta_{\max }}{\Delta_{0 i}(j)+\rho \Delta_{\max }}$;

where:

$\Delta_{0 i}(j)=\left|g_{i}(j)-g_{0 i}\right|$;

$\Delta_{\text {max }}=\max _{i=1}^{m_{k}} \max _{i=1}^{n} \Delta_{0 i}(j)$;

$\Delta_{\text {min }}=\min _{i=1}^{m=1} \min _{i=1}^{n} \Delta_{0 i}(j)$;

where $\rho$ represents the distinguishing coefficient $[0,1]$ and usually takes on a value of 0.5 implying a moderate distinguishing effect.

When $m_{k}$ is the number of indicators in each of $K$ categories and $n$ is the number of territories (countries, regions, municipalities, etc.), the significance of each indicator in each category can be calculated via the following equation:

(5) $\Gamma_{0 i}=\frac{1}{n} \sum_{j=1}^{n} \zeta_{0 i}(j)$; 
which refers to grey relational degree. If the weights $w(j)$ for the attributes are known, then the grey relational degree can be calculated as follows:

(6) $\Gamma_{0 i}=\sum_{j=1}^{n} \zeta_{0 i}(j) w(j)$;

where the sum of the attributes weights must be equal to 1 . Moreover, the computed relational degree is normalized with (7) because it represents the input weight for further analysis.

(7) $w_{\text {grey }}(i)=\frac{\Gamma_{0 i}}{\sum_{i=1}^{m_{k}} \Gamma_{0} i}$;

The calculated and normalized, grey relational degree $w_{\text {grey }}(i)$ represents the input grey weight $w_{i k}^{(l)}$ of the given indicator $i$ into the observed category $k$. When the grey weights are derived within all categories, scores for each category and each municipality $g_{k}^{(l+1)}$ are obtained as weighted sum of grey weights and corresponding indicator:

$g_{k}^{(l+1)}=\sum_{i=1}^{m_{k}} w_{i k}^{(l)} g_{i}(j)$;

In addition, for any observed territory, if $A_{k_{l}}^{(l)}$ is a set of input factors (normalized values of road safety indicators and corresponding grey weights) of the $k^{\text {th }}$ category in the $l^{t h}$ layer, the aggregated grey composite indicator is noted as in (9).

$G C I=1-\sum_{k_{L-1} \in A_{k_{L}}^{(L)}} w_{k_{L-1}}^{(L-1)} \ldots\left(\sum_{k_{l} \in A_{k_{l+1}}^{(L+1)}} w_{k_{l}}^{(l)} \ldots\left(\sum_{k_{2} \in A_{k_{3}}^{(3)}} w_{k_{2}}^{(2)}\left(\sum_{k_{1} \in A_{k_{2}}^{(2)}} w_{k_{1}}^{(1)} g_{k_{1}}^{(1)}\right)\right)\right) ;$

where:

$\sum_{k_{l} \in A_{k_{l+1}}^{(l+1)}} w_{k_{l}}^{(l)}=1$;

$k_{l}=1, \ldots, K^{(l)}$;

\section{SELECTION OF INDICATORS}

The complexity and multidisciplinary context of traffic safety in a given territory, using a composite index, can be represented by a single quantitative measure, which is an advantage over the use of individual indicators (Gitelman et al., 2010). This is achieved by applying appropriate methodologies to aggregate all selected indicators into a single comprehensive assessment of the road safety situation. In order for this assessment to be reliable and relevant, the choice of indicators as a first step is a very important and demanding task because the final assessment largely depends on that choice (Hermans, Van den Bossche \& Wets, 2009). For the selection of relevant indicators, it is first necessary to set a description of the phenomenon and its subcategories, the so-called road safety domains within which the relevant indicators will be selected. The first step of this process is to define the list of indicators that will potentially enter the final set used for the construction of the composite index, while the second step defines the criteria and methodology on the basis of which the selection will be made. Hermans (2009) presented the so-called an indicator card which provides an overview of the characteristics of each indicator individually. The card contains ten aspects according to which indicators are described and which help in decision-making, and in order to enter the selection, indicators must be relevant, measurable, understandable, data available, reliable, comparable, specific and sensitive. However, if a large number of performance indicators are available, some summarization is essential for the analysis (Bird et al., 2005). In contrast, as the unavailability of reliable and comparable road safety data limits the use of the best required indicators, many authors use the best-available indicators from each road safety domain.

LTSA (2000) presented the pyramidal structure of elements that affect traffic safety in a given territory, which consists of the structure and culture of the population, strategies and action plans to improve traffic safety, measures and programs to improve traffic safety, traffic safety indicators, final outcomes (traffic accidents) and total social costs. When analyzing the scientific literature, a great effort of experts is noticed to define one set of safety indicators that will best describe the road situation in a certain territory. The traditional approach to indicators (ETSC, 2001) presents three domains that affect the occurrence and consequences of traffic accidents, namely: traffic participants, vehicles and road infrastructure (environment), and the WHO (2011) states that every traffic accident is a direct consequence of a lack of functioning of one or more of the mentioned domains. Thus Hakkert et al. (2007b) within the SafetyNET project presented the methodological basis for defining indicators (indicator development begins with defining problems).

In the literature dealing with the creation of a composite index, the choice of indicators that will create the final safety score varies from author to author. Some authors use direct safety indicators such as the number of accidents or fatalities per capita, passenger kilometers or motor vehicles (Shen, Her- 
mans, Brijs, Wets \& Vanhoolf, 2012, Shen, Hermans, Bao, Brijs \& Wets, 2013, Bastos, 2014, Bastos et al., 2015, 2016); some use indirect indicators such as driver behavior, vehicles, and road infrastructure (Vis, 2005; Hermans et al., 2008b, Hermans, Brijs \& Geert 2008a, Hermans, Ruan, Brijs, Wets \& Vanhoolf, 2010, Hakkert \& Gitelman, 2007a; Hakkert et al., 2007b, Shen et al., 2011) and some authors use a combination of all of the above (Al-Haji, 2005, 2007, Wegman et al., 2008, Wegman \& Oppe, 2010, Gitelman et al., 2010, Chen, Wu, Chen, Wang \& Wang 2016) Summarizing, the most commonly used indicators for creating a composite index classified by EC domains are given as follows:

- Behavior: driving under the influence of alcohol, speeding, use of protective systems (seat belt, helmet, daytime running lights ...), use of telephone,

- Vehicles: fleet composition, fleet age

- Road (environment): length of the road network, quality of road infrastructure, health care, time until the arrival of assistance in the event of a traffic accident

In Montenegro, crash data are collected by the police, which is the main source of information for road fatalities and injuries. The 2012 Law prescribes that Ministry has to have electronic database of detailed information about the accidents, vehicles and persons that were involved in the accidents. Although, Ministry has database, it is not fully accurate as reports about accidents are filled in paper forms and only later are inputted in the electronic database.
Such data are not fully reliable and the robustness the composite index is based on the data from which it is constructed and its quality should improve in parallel with the improvement of the quality of the collected data and the development of the indicators used.

With respect to the literature and availability of data, in this research three types of indicators proposed by Al-Haji $(2005,2007)$ and Gitelman et al. (2010) are used, modified and classified into groups as presented in figure 1 . In addition to basic data on a territory, and in order to make an objective comparison between larger and smaller territories, it is necessary to use the degree of exposure. Exposure is a key element in the occurrence of an accident, so an adequate risk assessment is as important as the availability of reliable data on the number of road fatalities (Bastos, 2014). In the literature related to traffic safety, exposure is defined as the amount of movement within the traffic system (Hermans, 2008a). The most commonly used exposure measures are population, number of vehicles, kilometers traveled and number of passenger kilometers. Rates, the relationship between a certain type of consequences and the measure of exposure (such as the number of deaths in relation to the number of vehicles) is the most common way to measure and compare the security situation in a territory (e.g. PIN reports) but is also used as an indicator for composite index construction. All mentioned is the verification of selection of indicators from Safer product group.

It should be noted that indicators reflecting behavior from Safer people group should be the rates of people wearing seatbelts, rates of driving under the influence of alcohol, etc., but in Montenegro, such data are unavailable. Therefore, to address those be-

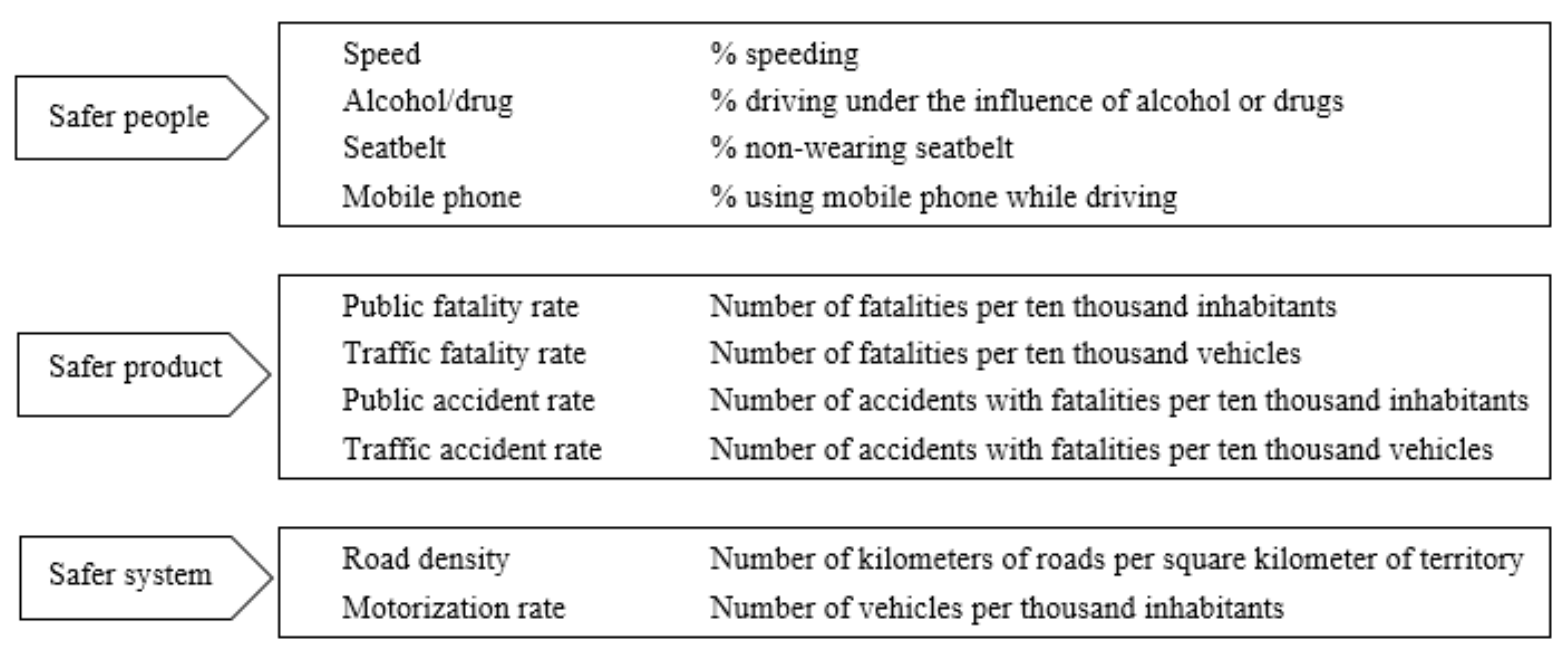

Figure 1. Selected road safety evaluation indicators. 
Table 1. Weights calculated using grey relational analysis.

\begin{tabular}{|c|c|c|c|c|c|}
\hline \multirow[t]{2}{*}{ Indicator group } & \multicolumn{2}{|c|}{ Weights } & \multirow[t]{2}{*}{ Indicators } & \multicolumn{2}{|c|}{ Weights } \\
\hline & $\Gamma_{0}^{(1)}$ & $w_{k}^{(1)}$ & & $\Gamma_{0}^{(1)}$ & $w_{k}^{(1)}$ \\
\hline \multirow[t]{4}{*}{ Safer people } & 0.6920 & 0.3713 & Speed & 0.5764 & 0.2422 \\
\hline & & & Alcohol/drug & 0.6864 & 0.2876 \\
\hline & & & Seatbelt & 0.7072 & 0.2971 \\
\hline & & & Mobile phone & 0.4121 & 0.1731 \\
\hline \multirow[t]{4}{*}{ Safer product } & 0.5650 & 0.3031 & Public fatality rate & 0.5952 & 0.2435 \\
\hline & & & Traffic fatality rate & 0.7883 & 0.3225 \\
\hline & & & Public accident rate & 0.3813 & 0.1560 \\
\hline & & & Traffic accident rate & 0.6799 & 0.2781 \\
\hline \multirow[t]{2}{*}{ Safer system } & 0.6068 & 0.3256 & Road density & 0.6349 & 0.5000 \\
\hline & & & Motorization rate & 0.6349 & 0.5000 \\
\hline
\end{tabular}

haviors, the number of violations recorded by the police (data are collected from the Ministry of interior) is considered. To describe the municipality more correctly, the number of violations is given as the rate per thousand inhabitants.

\section{RESULTS}

According to the proposed methodology for constructing one overall composite indicator, scores and ranking of territory can be obtained, as well as weights of the indicators included in the calculation (Table 1).

Also, road safety of territory can be monitored annually and with analyzing assigned weights the effects of implemented measures can be observed. Using a set of ten hierarchical road safety indicators in terms of final outcomes, the road users' behavior and basic territory information, 21 municipalities of Montenegro are evaluated via one composite index score. The relative weights for all of the three mentioned groups of indicators and the weights of each indicator in each group are obtained in terms of the grey relational degree. These weights can be used by policy makers for planning future measures.

The results show that in the overall safety score of Montenegro, the most influential group of indicators are those reflecting behavior because they received the highest grey weight score of 0.3713 . Taking into account that the data are not true rates but numbers of violations, the conclusion can be made that nonwearing a seatbelt represents one of the riskiest behaviors, with a grey weight of 0.2971 . In summary,
Table 2. Composite index of municipalities.

\begin{tabular}{|c|c|c|c|}
\hline Municipality & GCI score* & GCI*100 & Rank \\
\hline $\mathrm{AN}$ & 0,8733 & 87,33 & 4 \\
\hline $\mathrm{BR}$ & 0,6537 & 65,37 & 19 \\
\hline BA & 0,8577 & 85,77 & 5 \\
\hline BP & 0,8282 & 82,82 & 8 \\
\hline $\mathrm{BD}$ & 0,7312 & 73,12 & 16 \\
\hline $\mathrm{CT}$ & 0,8385 & 83,85 & 7 \\
\hline DG & 0,8987 & 89,87 & 3 \\
\hline $\mathrm{HN}$ & 0,8115 & 81,15 & 12 \\
\hline KL & 0,6894 & 68,94 & 17 \\
\hline $\mathrm{KO}$ & 0,7595 & 75,95 & 13 \\
\hline MK & 0,9094 & 90,94 & 2 \\
\hline NK & 0,748 & 74,80 & 14 \\
\hline PL & 0,9234 & 92,34 & 1 \\
\hline PV & 0,8461 & 84,61 & 6 \\
\hline PŽ & $\mathbf{0 , 8 1 9 9}$ & 81,99 & 10 \\
\hline PG & 0,2677 & 26,77 & 21 \\
\hline RO & 0,8234 & 82,34 & 9 \\
\hline ŠA & 0,6178 & 61,78 & 20 \\
\hline TV & 0,6779 & 67,79 & 18 \\
\hline UL & 0,746 & 74,60 & 15 \\
\hline$\check{Z ̌ B}$ & 0,8185 & 81,85 & 11 \\
\hline
\end{tabular}


grey relational analysis can measure the relative importance among indicators, implying that those with higher grey weight values are more significant than those with lower grey weights. By analyzing the assigned weights, the strategies can be made which can be adopted either by the government authorities or individually on a local basis. When calculated, the grey weights are further combined with the municipality performances to obtain one composite indicator. In addition, based on the results the rank of the territories can be established. The proposed approach provides a more reasonable and encompassing measure of performance, based on which the overall ranking position of municipalities is obtained. Ranking is conducted in such a manner that the municipality with a higher safety level occupies a higher place. For Montenegro, PL is ranked first, followed by MK, DG and AN, as shown in Table 2 . This result is not a surprise given that those municipalities are all small ones with low motorization levels and no main roads in their territories.

\section{DISCUSSION AND CONCLUSION}

It is very important to adequately address issues of road accidents and traffic injuries, as they remain great problems for the public health system. Aggregation of different variables into one road safety performance index is a popular concept in evaluating road safety and comparing the performance of territories. This paper presents the development of a novel and innovative weighting methodology using grey relational analysis. Based on the proposed model, ten hierarchical road safety indicators were selected in terms of a two-layered model with three categories related to behavior, safety and system. Grey weights are assigned to categorized indicators in each layer, and the grey road safety composite indicator for each of 21 selected municipalities in Montenegro is calculated. With relatively high assigned weights, the riskiest domain is targeted. The highest weight assigned to the indicator concerning the not wearing the seatbelt shows that it represents the most obscure negative behavior in Montenegro. However, it cannot be claimed that not wearing a seat belt has the greatest impact on the safety situation, but it certainly shows a field that should be improved with concrete actions and preventive measures. In this way, the experts were given the opportunity of practical application when adopting future preventive measures with the aim of improving the security situation. If a larger number of safety indicators are considered in the analysis, the results may be more comprehensive. Moreover, to create more precise and organic conclusions, there is a need to implement indicators related to perception and attitudes of both, public and experts. Therefore, in the future researches, effort should be gained to conduct such surveys and provide answers to the questions raised. There is no unique number of layers and categories, which is an advantage and a deficiency because absolute freedom is given to the researcher in choosing best available data for a particular subject of research. Therefore, sensitive analysis should be implemented, and the need exists to define standardized categories of indicators as well as the indicators themselves that can best describe the level of road safety of territories and are also applicable to underdeveloped countries with a lack of data. Also, periodic analyzes can be performed and changes in influencing factors can be determined over time. Given that the GRA is normalization-based methodology, the calculated results might vary based on type of normalization, which is the largest shortcoming of this method and further research should investigate the normalization method that best fits the data representing road safety.

\section{REFERENCES}

Al- Haji, G. (2005). Towards a Road Safety Development Index (RSDI)-Development of an International Index to Measure Road Safety Performance. Department of Science and Technology. Norrköping: Linköping University. Retrieved from http://www. divaportal.org/smash/get/diva2:20332/FULLTEXT01.pdf

Al- Haji, G. (2007). Road Safety Development Index (RSDI): Theory, Philosophy and Practice. Department of Science and Technology. Norrköping: Linköping University. Retrieved from http://ir.nmu.org.ua/bitstream/handle/123456789/126470/0 bb47fc915be24e29d6a9f7912a5abe3.pdf?sequence=1

Bao, Q. (2010). Multi-criteria decision making techniques for combining different sets of road safety performance indicators into an overall index. Master thesis, Interfaculty institute transportation sciences, University of Hasselt. Retrieved from https://documentserver.uhasselt.be/bitstre am/1942/12553/1/08275732009335.pdf

Bastos, J. T. (2014). Road safety strategic analysis in Brazil: Indicator and index research. Doctoral Thesis, Escola de Engenharia de São Carlos, Universityof São Paulo, São Carlos. Retrieved from http://www.teses.usp.br/teses/disponiveis/18/18144/ $\underline{\text { tde-08042015-103747/ }}$

Bastos, J. T., Shen, Y., Hermans, E., Brijs, T., Wets, G., \& Ferraz, A. C. P. (2015). Traffic fatality indicators in Brazil: state di- 
agnosis based on data envelopment analysis research. Accident Analysis and Prevention, 81, 61-73. https://doi.org/10.1016/j. aap.2015.01.024

Bastos, J. T., Shen, Y., Hermans, E., Brijs, T., Wets, G., \& Ferraz, A. C. P. (2016). Road safety performance in Brazil: towards a composite indicator. In 17th International Conference Road Safety On Five Continents (RS5C 2016), Rio de Janeiro, Brazil, 17-19 May 2016 (pp. 1-12). Statens väg-och transportforskningsinstitut. Retrieved from http://www.divaportal.org/smash/ record.jsf?pid=diva2\%3A927896\&dswid $=-5643$

Bird, S.M., Cox, D., Farewell, V.T., Goldstein, H., Holt, T., \& Smith, P.C., (2005). Performance indicators: good, bad, and ugly. Journal of the Royal Statistical Society: Series A, 168(1), 1-27. https://doi.org/10.1111/j.1467-985X.2004.00333.x

Chen, F., Wu, J., Chen, X., Wang, J., \& Wang, D. (2016). Benchmarking road safety performance: Identifying a meaningful reference (best-in-class). Accident Analysis and Prevention, 86, 76-89. https://doi.org/10.1016/j.aap.2015.10.018

Deng, J. (1989). Introduction to grey system theory. The Journal of Grey System, 1(1), 1-24. Retrieved from https://link.springer. com/chapter/10.1007/978-3-642-16158-2_1

European Council. (2010) European Council conclusions on road safety. 2 December 2010; paragraph 21, ST 16951/10. Retrieved from https://www.gov.uk/government/speeches/eutransport-council--20

European Transport Safety Council. (2001). Transport Safety Performance Indicators. Brussels, http://etsc.eu/wp-content/ uploads/Transportsafety-performance-indicators.pdf

Gitelman, V., Doveh E., \& Hakkert S. (2010). Designing a composite indicator for road safety. Safety Science. 48, 1212-1224. https://doi.org/10.1016/j.ssci.2010.01.011

Hakkert, S., \& Gitelman, V. (2007a). Road Safety Performance Indicators: Manual. Loughborough University. Deliverable D3.8 of the EU FP6 project SafetyNet. Retrieved from http://erso. swov.nl/safetynet/fixed/WP3/sn_wp3_d3p8_spi_manual.pdf

Hakkert, S., Gitelman, V., and Vis, M. (2007b). Road Safety Performance Indicators: Theory. Loughborough University. Deliverable D3.6 of the EU FP6 project SafetyNet. Retrieved from http:// erso.swov.nl/safetynet/fixed/WP3/sn_wp3_d3p6_spi_theory.pdf

Hermans, E., Brijs, T., and Geert, W. (2008a). Developing a Theoretical Framework for Road Safety Performance Indicators and a Methodology for Creating a Performance Index. Diepenbeek: University of Hasselt Retrieved from https://doclib. uhasselt.be/dspace/handle/1942/10796

Hermans, E., Ruan, D., Brijs, T., Wets, G., and Vanhoof, K. (2010). Road safety risk evaluation by means of ordered weighted averaging operators and expert knowledge. KnowledgeBased Systems, 23(1), 48-52. https://doi.org/10.1016/j.knosys.2009.07.004

Hermans, E., Van den Bosshe, F., \& Wets, G. (2008b). Combining road safety information in a performance index. Accident Analysis and Prevention, 40, 1337-1344, https://doi. org/10.1016/j.aap.2008.02.004

Liu, Y., Huang, X., Duan, J., \& Zhang, H. (2017). The assessment of traffic accident risk based on grey relational analysis and fuzzy comprehensive evaluation method. Nat Hazard. 88, 1409-1422. https://doi.org/10.1007/s11069-017-2923-2

LTSA (2000). Road safety strategy 2010. A consultation document. National Road Safety Committee. http://www.ltsa.govt. $\underline{\mathrm{nz} / \text { publications/rs-framework.html }}$

Lu, M., \& Wevers, K. (2007). Application of grey relational analysis for evaluating road traffic safety measures: advanced driver assistance systems against infrastructure redesign. IET Intelligent Transport Systems, 1(1), 3-14. http://dx.doi.org/10.1049/ iet-its:20060022

Ma, Z., Shao, C., Ma, S., \& Ye, Z. (2011). Constructing road safety performance indicators using Fuzzy Delphi Method and Grey Delphi Method. Expert Systems with Applications, 38, 1509-1514. https://doi.org/10.1016/j.eswa.2010.07.062

OECD \& European Commission. (2008) Handbook of constructing composite indicators. Methodology and user quide. Paris. ISBN 978-92-64-04345-9. Retrieved from https://www. oecd.org/sdd/42495745.pdf

René, S. H., Becker, U., \& Manz, H. (2016). Grey system theory time series prediction applied in road traffic safety in Germany. IFAC-PapersOnLine, 49(3), 231-236. https://doi. org/10.1016/j.ifacol.2016.07.039

Shen, Y., Hermans, E., Ruan, D., Wets, G., Brijs, T., \& Vanhoof, K. (2011). Modeling qualitative data in data envelopment analysis for composite indicators. International Journal of System Assurance Engineering and Management, 2(1), 21-30. https://doi. org/10.1007/s13198-011-0051-Z

Shen, Y., Hermans, E., Brijs, T., Wets, G., \& Vanhoof, K. (2012). Road safety risk evaluation and target setting using data envelopment analysis and its extensions. Accident Analysis and Prevention. 48. 430-441. https://doi.org/10.1016/j.aap.2012.02.020

Shen, Y., Hermans, E., Bao, Q., Brijs, T., \& Wets, G. (2013). Road safety development in Europe: A decade of changes (2001-2010). Accident Analysis and Prevention. 60. 85-94. http://dx.doi.org/10.1016/j.aap.2013.08.013

Vis, M. A. (2005). Deliverable D3.1: State of the art Report on Road Safety Performance Indicators. Loughborough University. SWOV. Retrieved from http://erso.swov.nl/safetynet/fixed/WP3/ Deliverable\%20wp\%203.1\%20state\%20of\%20the\%20art.pdf

Wegman, F., \& Oppe, S. (2010). Benchmarking road safety performances of countries. Safety Science, 48, 1203-1211. https:// doi.org/10.1016/j.ssci.2010.02.003

Wegman, F., Commandeur, J., Doveh, E., Eksler, V., Gitelman, V., Hakkert, S., et al. (2008). SUNflowerNext: Towards a composite road safety performance index. Leidschendam: SWOV Institute for Road Safety Research. Retrieved from http://www. swov.nl/rapport/sunflower/sunflowernext.pdf

World Health Organization. (2011). Decade of Action for Road Safety 2011-2020. Saving millions of lives. 2011; Retrieved from http://www.who.int/violence_injury_prevention/publications/road_traffic/saving_millions_lives_en.pdf?ua $=1>$

World Health Organization. (2018). Global status report on road safety. Geneva. Licence: CC BYNC-SA 3.0 IGO. ISBN 978-92-4-156568-4 Retrieved from https://www.who.int/violence_injury_prevention/road_safety_status/2018/en/ 